\title{
Create Heijunka 5's Matrix to Control the Dynamic Gemba as Lean Tool
}

\author{
Ahmed M. Abed \\ Industrial Engineering Department, Zagazig University, Zagazig, Egypt \\ Email address: \\ GembaConsultingOffice@gmail.com \\ To cite this article: \\ Ahmed M. Abed. Create Heijunka 5's Matrix to Control the Dynamic Gemba as Lean Tool. Journal of Human Resource Management. \\ Vol. 3, No. 2, 2015, pp. 6-16. doi: 10.11648/j.jhrm.20150302.11
}

\begin{abstract}
The heijunka tracking matrix has a direct impact on turn overtimes of the inventory to revamp existing orders as well as new technique, and increase the utilization of the inventory' labors by eliminating the waste in transportation and overprocessing actions. The tracking problem is interested in rearranging the location of VSM (e.g., items, pallets and stations) in a grouping of cellular aspect using 5'S concepts, which increase performance level. One of the successful recommendations used in this context is traveler salesman technique but with periodically update (i.e., Dynamic Gemba), it may be need reformulation. Its importance is the capture of work, information, and material (WIP, setup time, process time/unit, error rates, idle time, etc.) which is essential in quantifying and determining waste in terms of cost, delivery time and transportation frequency. This paper is interest in review the dynamic Gemba model to improve the inventory handling via modifying the traveler salesman model with aided proposed heuristic procedures, which are interested in arrange the inventory in minimum time and maximum flexibility in preparing the different orders. The Gemba tasks displayed via (Gemba KPI/DOE board) which contain cost and time information (NNVA: preparing tasks, VA: traveling |tracking tasks and NNVA: unloading tasks). The optimized cost and time analysis after reducing NNVA time and total VA time were sent to the central heijunka matrix. The methodology which includes elimination movements, motion and extra actions wastes are lean, and aim to increase the ability of prepare a lot of service in minimum time.
\end{abstract}

Keywords: Lean, Manufacturing Facility Layout, Gemba, Heijunka Cellular Manufacturing, KPI in Six-sigma

\section{Introduction}

The Gemba is a Japanese word may use in different sentence such as Japanese detectives call the crime scene Gemba, and Japanese TV reporters may refer to themselves as reporting from Gemba. In business, Gemba refers to the place where value is created; in manufacturing the Gemba is the factory floor. It can be any "site" such as a construction site, sales floor or where the service provider interacts directly with the customer [1]. In lean manufacturing, the idea of Gemba is that the problems are visible, and the best improvement ideas will come from going to the Gemba. The Gemba may be static or dynamic. The dynamic Gemba changes every visit. The Gemba walk, much like Management By Walking Around (MBWA) to study the best procedures increase performance of executing activities that takes management to the front lines to look for waste and opportunities to practice Gemba heijunka, or practical shop floor improvement. A heijunka is a concept originally created by Toyota for achieving a smoother flow. This paper interest in creating (The heijunka DOE board matrix) which is generally a board schedule which is divided into a grid of KPI equations. Each variable of KPI representing a specific level for significant variable impact on increasing stores performance. The KPI equation contain some Colored (green: executed at the first, yellow: ready to execute, red: postpone to end of track) positions representing individual objective are placed on the heijunka board to provide a visual representation of the good track. The heijunka board make it easy to see what is the smooth track of tasks are queued for completing and for when they are scheduled.

Gemba walks denote the action of going to see the actual process, understand the work, ask questions, and learn [11][12]. It is known as one fundamental part of Lean management philosophy [13].

Gemba Walk is designed to allow leaders to identify existing safety hazards, observe human resources and equipment conditions, ask about the practiced standards, gain knowledge about the work status and build relationships with 
employees [14]. It is different from classic management style of MBWA. The objective of Gemba Walk is to understand the value stream and its problems rather than review results or make superficial comments [15]. A long with Genchi Genbutsu or "Go, Look, See", Gemba Walk is one of the 5Lean guiding principles that should be practiced by Lean leaders on a daily basis. The Gemba walk is an activity that takes management to the front lines to look for waste and opportunities to practice Gemba kaizen, or practical shopfloor improvement [16].

Dynamic Gemba may be classified an application of group technology (GT), utilizes the concept of divide and conquer and involves the grouping of resources into cells responsible for manufacturing or assembly of similar parts or products [8]. The main reason that stores are attracted towards implementing $\mathrm{CM}$ layout is that the benefits of $\mathrm{CM}$ and Layout designs, which can normally be realized with relatively low capital investment by relocating and possibly duplicating certain resource as opposed to other automated strategies.

The design for cellular manufacturing involves three stages (i) grouping of items and production equipment into cells, (ii) allocation of the orders cells to areas within the shop floor (inter-cell or facility layout), and (iii) layout of the machines within each cell (intra-cell or machine layout)[16].

Although the concept of generally out problem has been studied for decades [10] for a comprehensive review of such models, certain specific and practical constraints normally present in a real $\mathrm{CM}$ environment restrict the implementation of general-purpose layout models [6].

A major difficulty with the existing CM models is that they has no leveling and consider the travelling cost as the sole criterion and the layout with the minimum cost is presented to the decision maker (DM), ignoring many real-world constraints. Because of these limitations many industrial layout designs are being developed by the companies based on their in-house expertise.

This paper demonstrates the capability of handling the inventory via the heijunka DOE board matrix which depends on dynamic Gemba for one of bathtub manufacturing company in Egypt. Furthermore, the capability of the proposed model in capturing realistic constraints such as closeness relationships, location restrictions/preferences, orientations, aisle structures and irregular site shapes is also presented. A facility layout is an arrangement of everything needed for production of goods or delivery of services. A facility is an entity that facilitates the performance of any job.

\section{The Track of Dynamic Gemba}

This section presents the track of the dynamic Gemba which impact on delivery time via the heijunka a KPI/DOE board matrix. "Fig.1" reviews the formulation of the Gemba and the position of proposed heuristic procedures of 5'S in treating traveler sales man problem in heijunka layout, which has specific property as rapid modification.

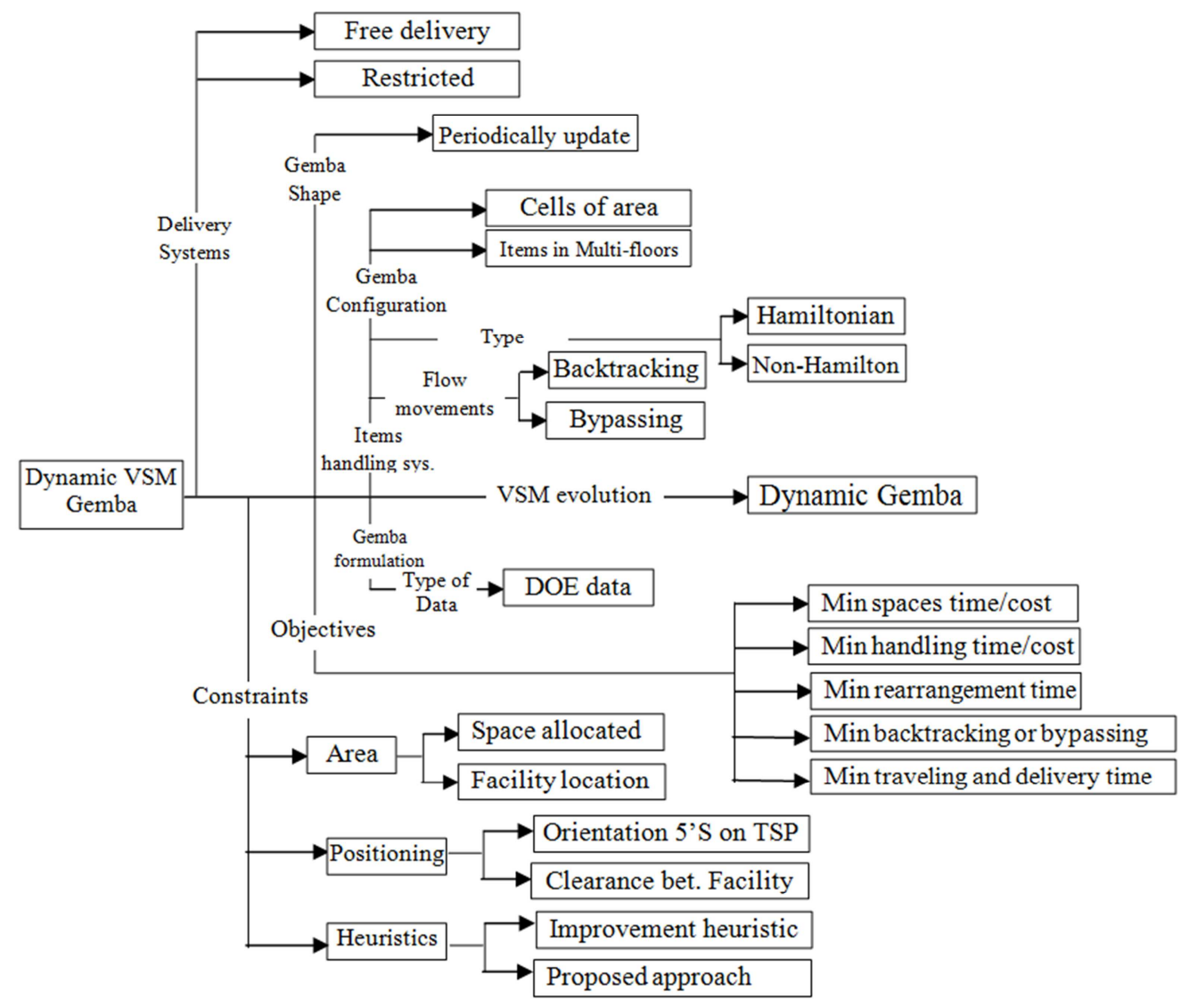

Fig. 1. The tree of the different factors for the dynamic Gemba VSM. 
"Fig.1"illustrates a possible rough tree representation of the different factors for the dynamic Gemba layout and its related constraints. The proposed model is compared with its validate with the current state (as-is), this figure present a summary for the problem scope.

\section{Proposed Heuristic Model}

The proposed algorithm deal with movable (e.g. items) and fixed (e.g. cities) stations. The two types of stations have shared in the same objectives, which are reducing total delivery time and costs. The proposed procedures are divided into two phases, the first interested in rearrange the movable items in multi-floors depend on strongly KPI relationship using the heijunka matrix. While reducing the travelling time between the fixed stations in according to analyze the KPI of the delivery time after fed in the heijunka matrix is aim of the second phase.

A. Phase-1: Construct the Gemba Cellular Arrangement

This phase is concerned with reducing the buffers of the items between the different stations that appeared in VSM via grouping heijunka cells.

1. Determine the KPI for neighboring Hamiltonian stations

2. Construct the DOE for the KPI significant factors

3. Feeding the heijunka matrix with KPI values

4. Sum the values for every row and column.

5. Choose the largest value, whether from row or column for every station (item\|city).

6. Arrange these values in ascending order.

7. Compilation of two smaller numbers, and then put the integrated station (item||city) in its position of the ascending order as done in step-3.
8. Continue until there remains not one single station (item $\|$ city), or the collected values become greater than the larger summation of all collected numbers that computed in step-1, whether for row or column.

9. Determine the cells as appeared in step-5.

10. Construct the Cells' table and its related station (item $\|$ city).

11. Arrange the related station (item $\|$ city) with respect to its strong KPI.

12. When we put the station (item $\|$ city) into place, examine the row for the executed and the extent of his KPI with other already existing, and then the level is chosen depending on the intensity of the KPI, either ground level or upper level.

13. Continue until put all station (item $\mid$ city) in the 3-D studio dynamic Gemba.

14. These attempts depend on heuristic procedures as numbered in phase-1. If the utilization of the station " $U_{m / c}$ " and a Traveling Time $T T_{\text {complet.flow }}$ for any iteration is greater than next iteration, then go on, but if them equal then stop and become known.

\section{The Total Cost Formulation}

The objective functions studying the cost of traveling between movable or fixed stations. These functions depend on some sets such as the item type $(i)$, intermediate buffers $(b)$,the holding cost that appeared when stations late to pull item to serving order $(\mathrm{h})$, supermarket capacity $(\mathrm{sm})$, tact time $(t)$, also have two parameters $a_{i j}$ is the preparing time for item $i$ on a specific station and $b_{i s}$ which denote to unit transferee time for product $i$ via supermarkets.

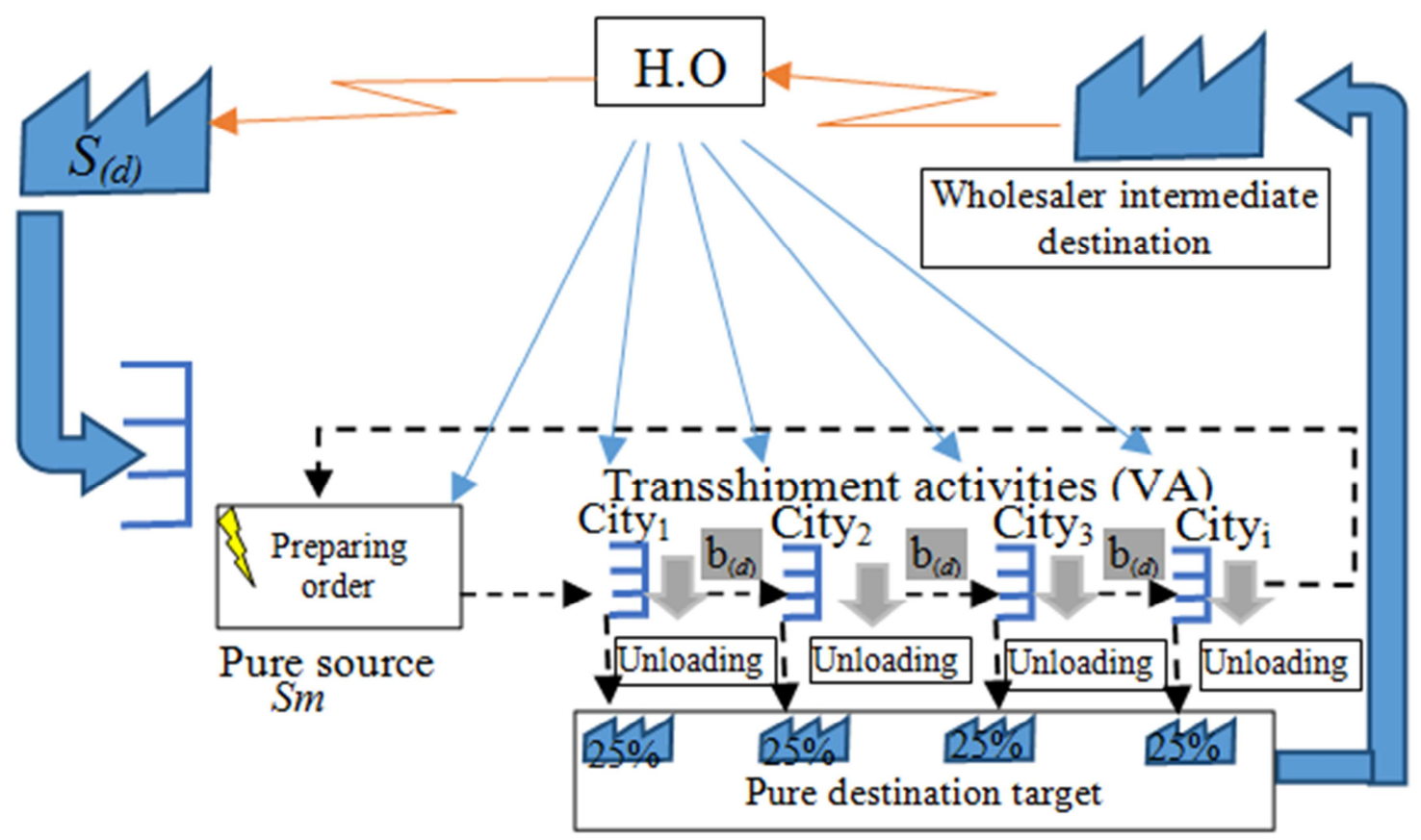

Fig. 2. Gemba of the travelling chart. 
The intermediate inventories addressed as different stores as illustrate in "Fig.2", these inventories were controlled with respect to the pulling operation. The cost computations were illustrated in four types of obj. function sand some constraints represented from"Eq.1 toEq.18”.

B. Phase-2: Economic Transportation Distance and Time

The economic distance between different stations depends on the transportation cost and market profit form. If there is any units not handled weather transportation system become in position will increase transportation cost and that is a worst case.

The fixed cost of the transportation system is $\$ 4 \mathrm{~km} /$ day; the cost of handling items during trip is $\$ 35 \mathrm{~km} /$ day above the fixed cost. The historical file illustrates that there is a fluctuation between 250 and $500 \mathrm{~km} /$ trip, if the items handled in its time will save $\$ 120$ /day (orders) but else if not handled in time (late, postponed or canceled) will cost company $\$ 160$ for transportation and $\$ 45$ for inventory.

The next simulation code used to estimate the optimum quantity to shipping and transported during economic trip to design a suitable super-market:

$\%$ number of simulation runs $\mathrm{n}=10000$;

Cartons $=[25: 91] ; \% \% ? ? ? ? ? ?$ order $=[100: 350]$;

minimum_move_condition $=(0.175 *$ Cartons $)-(133)$;

fork $=1: 66$

cum_saves $=0$;

form $=1: \mathrm{n}$

void=91-floor(rand*(91-26));

ifvoid $<=$ Cartons $(\mathrm{k})$

partial_saves $=2.55 * 1.8 * 3 *(91-\operatorname{Cartons}(\mathrm{k})$-order $(\mathrm{k}))$;

else

partial_saves $=$ order $(\mathrm{k})+(90 *($ Cartons $(\mathrm{k})$-void $))-2 *$ void;

end

saves=partial_saves-minimum_move_condition(k);

cum_saves $=$ cum_saves + saves;

end

expected_saves $=$ cum_saves $/ \mathrm{n}$;

$\mathrm{p}(\mathrm{k}, 1)=\operatorname{Cartons}(\mathrm{k})$;

$\mathrm{p}(\mathrm{k}, 2)=$ expected_saves;

end

$\operatorname{plot}\left(\mathrm{p}(:, 1), \mathrm{p}(:, 2),{ }^{\prime}+', \mathrm{p}(:, 1), \mathrm{p}(:, 2),{ }^{\prime}-'\right)$, xlabel ('Ideal Distance vs. void fill'), ylabel ('Transportation saves\$')

"Fig.3" illustrates the ideal\# of cartons save the transportation costis more than 63 carton/trip that represents the minimum void for the pace maker quantity.

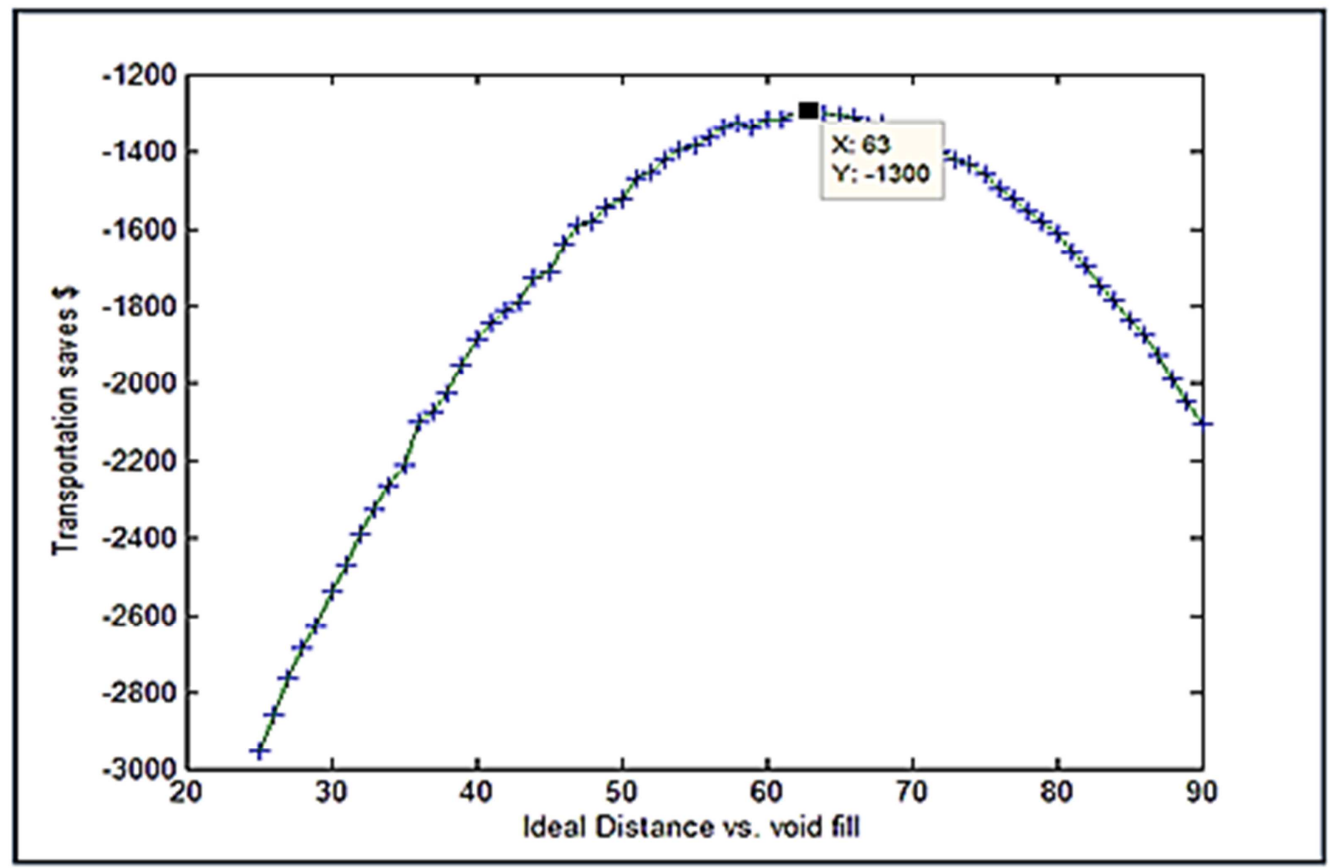

Fig. 3. The ideal tripdistance vs. void sipping cost.

The Abbreviations used in the objective functions and proposed constraints:

\begin{tabular}{llll}
\hline Parameters & \multicolumn{2}{l}{ Decision variables } \\
\hline$a_{i m}$ & Order preparing time for station $i$ from station $m$ & $X_{i m t}$ & Production quantity of product $i$ produced from $m$ in $m i n$ \\
$b_{i s}$ & Order preparing time for station $i$ in supermarket $s m$ & $R A_{m t}$ & Available time of supermarket in min. \\
$R_{m t}$ & Available time of labor in $\min$. & $O A_{m t}$ & Over time capacity used in supermarket $\operatorname{sm}$ in $m i n$. \\
$C A P O_{i t}$ & Overtime capacity of order $i$ in period $t$. & $O_{i m t}$ & Over time capacity of product $i$ stay on station $m$ in $\min$. \\
$C A P O A_{i t}$ & Overtime capacity consumed in $\mathrm{sm}$. & $I_{i m t}$ & Inventory of product $i$ produced from $m$ in $\min$ \\
\hline
\end{tabular}




\begin{tabular}{|c|c|c|c|}
\hline \multicolumn{2}{|c|}{ Parameters } & \multicolumn{2}{|c|}{ Decision variables } \\
\hline$P R_{t}$ & Regular time working capacity in man-hours & $P L_{\text {int }}$ & Amount of deficit of product $i$ in period $t$ in $\min$ \\
\hline$P O_{t}$ & Overtime working capacity in man-hours & $L P_{i s m t}$ & Amount of product $i$ transported from $m$ to $s m$ \\
\hline$N W$ & Total number of workers to be assigned to $s m$ & $L Q_{\text {ismt }}$ & Amount of product $i$ transported from $s m$ to $m$ \\
\hline$D_{i s m t}$ & The quantity of items $i$ demanded by $s m$ & $W_{s m t}$ & Workforce assigned to pull supermarket \\
\hline$T Q_{s m}$ & Product holding capacity of $s m$ as raw items & $P_{i s t}$ & Amount of end of period $s m$ of product $i$ in $\min$ \\
\hline$T P_{s m}$ & Product holding capacity of $s m$ as semi-finish & $Q L_{\text {ismt }}$ & Amount of deficit of product $i$ at $s m$ in period $t$ \\
\hline$T A_{m s m}$ & Transportation time from $m$ to $s m$ in transshipment & $Q_{i s t}$ & Amount of $s m$ of product $i$ in the end \\
\hline$T C S_{s m t}$ & $\begin{array}{l}\text { The available distribution time of } s m \text { in } \\
\text { transshipment }\end{array}$ & $T L P_{m s m t}$ & The number of travel needed from $m$ to $s m$ in transshipment \\
\hline$T B_{m s m}$ & Transportation time from $m$ to $s m$ in pure source & $T L Q_{m s m t}$ & The number of travel needed from $m$ to $s m$ in pure mach. \\
\hline TCSS & The available distribution time, & $T P Q_{m s m t}$ & The number of travel needed from $m$ to $s m$ in transshipment \\
\hline$T B S$ & Loading capacity of a Freight car, per travel & $P Q_{\text {imsmt }}$ & Amount of product $i$ transported from $s m$ to next $s m$ \\
\hline$C P_{i m}$ & Unit variable production cost of product $i$, on $m$ & $\mathrm{COW}_{m}$ & Cost of the Fright car / hrs \\
\hline$C I_{i m}$ & Cost of supermarket, for product $i$ from $m$ & $C P_{i m}$ & Cost of the supermarket in transshipment sectors \\
\hline$C L_{i m}$ & Transportation cost & $S Q_{i s m}$ & Cost of holding Unit from product $i$, in $s m$ \\
\hline$C O_{m}$ & The cost of the Overtime for $m$ & $S Q Q_{i s m}$ & Cost of shortage product $i$, if reduced in $s m$ \\
\hline$C R_{m}$ & Cost of available regular time & $C T L Q_{m s m}$ & Cost of traveling needed $i$ from sm to $m$ \\
\hline
\end{tabular}

- The objective functions:

Objective-1, Profit:

$$
\begin{aligned}
& \sum_{i=1}^{12} \sum_{m=1}^{7} \sum_{t=1}^{8}\left(X_{i m t} P R C_{i}\right)-\left[\sum_{i=1}^{12} \sum_{m=1}^{7} \sum_{t=1}^{8}\left(C P_{i m} \times X_{i m t}+C I_{i m} \times I_{i m t}+C L_{i m} \times P L_{i m t}\right)+\sum_{j=1}^{7} \sum_{m}^{7} \sum_{t}^{8}\left(C O_{m} \times O_{j m t}\right)\right. \\
& \left.+\sum_{s m=1}^{7} \sum_{m}^{7} \sum_{t}^{8}\left(C R_{m} \times R A_{s m t}+C O_{m} \times O A_{s m t}+C O W_{m} \times O A W_{s m t}\right)\right]
\end{aligned}
$$

Objective-2, Delivery Cost:

$$
\begin{aligned}
& \sum_{i=1}^{12} \sum_{m=1}^{7} \sum_{t=1}^{8}\left(C P_{i m} \times X_{i m t}+C I_{i m} \times I_{i m t}+C L_{i m} \times P L_{i m t}\right)+\sum_{J=1}^{12} \sum_{m=1}^{7} \sum_{t=1}^{8}\left(C O_{m} \times O_{j m t}+C O W_{m} \times O W_{j m t}\right) \\
& \left.+\sum_{s m=1}^{7} \sum_{m}^{7} \sum_{t}^{8}\left(C R_{m} \times R A_{s m t}+C O_{m} \times O A_{s m t}+C O W_{m} \times O A W_{s m t}\right)\right]
\end{aligned}
$$

Objective-3, Super-Market Cost in transshipment sector:

$$
\sum_{i=1}^{12} \sum_{m=1}^{7}\left(S Q_{i s m} \times Q_{i s m t}+S Q Q_{i s m} \times Q L_{i s m t}\right)+\sum_{J=1}^{12} \sum_{m=1}^{7}\left(T L Q_{m s m t} \times C T L Q_{m s m}\right)+\sum_{s m}^{7} \sum_{t}^{8}\left(T P Q_{p s m t} \times C T P Q_{p s m}\right)
$$

Objective-4, Super-Market Cost in pure sources or destinations sectors:

$$
\sum_{i=1}^{12} \sum_{p=1}^{7} \sum_{t=1}^{8}\left(S P_{i m} \times P_{i m t}+S P P_{i m} \times W L_{i m t}\right)+\sum_{m=1}^{7} \sum_{p=1}^{7} \sum_{t=1}^{8}\left(T L P_{m p t} \times L P C_{m p}\right)
$$

- The related constraints:

$$
\begin{gathered}
\sum_{i=1}^{12} a_{i m} \times X_{i m t}-R_{j t}-O_{j m t} \leq 0 \ldots . \forall . m, t \\
\sum_{i=1}^{12} b_{i s} \times X_{i m t}-R A_{m t}-O A_{m t} \leq 0 \ldots . \forall . s, m, t
\end{gathered}
$$




$$
\begin{aligned}
& O_{i m t}-C A P O_{i t} . . \forall . i, t \\
& O A_{i m t}-C A P O A_{i t} \leq 0 \\
& \sum_{i}^{12} Q_{i s m t} \leq T Q_{s m} \\
& \sum_{m}^{7} P_{i s m t} \leq T P_{s m} \\
& Q_{i s t-1}+\sum_{m=1}^{7} P Q_{i s m t}+\sum_{s m}^{5} L Q_{i s m t}+Q L_{i s m t}-Q_{i s t}=D_{i s m t} . . \forall . i, s m, t \\
& \sum_{m}^{7} T A_{m s m} \times T L P_{m s m t} \leq T C S_{s m t} \\
& \sum_{m=1}^{7} T B_{m s m} \times T L Q_{m s m t}+\sum_{m}^{7} T C_{m s m} \times T P Q_{m s m t}+Q L_{i s m t} \leq T C S S_{s m t} \\
& T L P_{m s m t} \geq\left[\left(\sum_{i}^{12} L P_{i m s m t}\right) / T B S\right] \\
& T L Q_{m s m t} \geq\left[\left(\sum_{i}^{12} L Q_{i m s m t}\right) / T B S\right] \\
& T P Q_{m s m t} \geq\left[\left(\sum_{i}^{12} P Q_{\text {imsmt }}\right) / T B S\right] \\
& X_{i m t}+I_{i m t-1}-I_{i m t}+P L_{i m t}=\operatorname{Dem}_{i m t} . \forall \cdot i, m, t \\
& X_{i m t}+I_{i m t-1}-I_{i m t}=\sum_{p}^{3} L P_{i m s t}+\sum_{s m}^{5} L Q_{i s m t} . . \forall . i, m, t \\
& R A_{s m t}-P R_{t} \times W_{s m t}=0 \\
& C A P O A_{s m t}-P O_{t} \times W_{s m t}=0 \\
& \max \left(W_{s m}\right)-W_{s m t}-\min \left(W_{s m}\right)=N W \geq 0 \\
& P_{i s t-1}+\sum_{m=1}^{7} L P_{i m p t}-P_{i s t}=\sum_{s m}^{5} P Q_{i s m t} . . \forall . i, s m, t
\end{aligned}
$$

Subjectto: $X_{i m t}, I_{i m t}, P L_{i m t}, O_{i m t}, W_{s m t}, O A_{m t}, D_{i s m t}, P_{i s t}, Q_{i s t}, Q L_{i s m t}, L P_{i s m t}, L Q_{i s m t}, P Q_{i m s m t} \quad \geq 0$ 


\section{Construct the DOE for the KPI}

The DOE depends on KPI (delivery time $)=f($ preparing order time, travelling time, unloading time ) * $\mathrm{f}^{*}$ handling factor. All values is divided by 10 . The frequency value means the staying time in specific node, the standard staying time have a value (1) or its multiplication.

In our problem we needed to specify the delivery time for every node and number of strokes (f) for every node on the map.

Table 1. The doe of thekpitest.

\begin{tabular}{|c|c|c|c|c|c|c|c|c|c|c|c|c|}
\hline \multirow{2}{*}{$\begin{array}{l}\text { Run } \\
\text { number }\end{array}$} & \multirow{2}{*}{$\begin{array}{l}A(\min ) \\
(10: 20) \\
\text { preparing } \\
\text { time: } X_{1}\end{array}$} & \multirow{2}{*}{$\begin{array}{l}B(\text { min) } \\
(50: 240) \\
\text { travelling } \\
\text { time: } X_{2}\end{array}$} & \multirow{2}{*}{$\begin{array}{l}\mathrm{C}(\min ) \\
(15: 60) \\
\text { unloading } \\
\text { time: } \mathrm{X}_{3} \\
\end{array}$} & \multirow[t]{2}{*}{ AB } & \multirow[t]{2}{*}{ AC } & \multirow[t]{2}{*}{ BC } & \multirow[t]{2}{*}{$\mathbf{A B C}$} & \multicolumn{4}{|c|}{$\begin{array}{l}\text { Y [KPI: delivery time in } \min (\text { four } \\
\text { replicates, } n=4 \text { ] }\end{array}$} & \multirow{2}{*}{ Total } \\
\hline & & & & & & & & 1 & 2 & 3 & 4 & \\
\hline 1 & -1 & -1 & -1 & +1 & +1 & +1 & -1 & 18.2 & 18.9 & 12.9 & 14.4 & 64.4 \\
\hline 2 & +1 & -1 & +1 & -1 & +1 & -1 & -1 & 27.2 & 24.0 & 22.4 & 22.5 & 96.1 \\
\hline 3 & -1 & +1 & +1 & -1 & -1 & +1 & -1 & 15.9 & 14.5 & 15.1 & 14.2 & 59.7 \\
\hline 4 & +1 & +1 & -1 & +1 & -1 & -1 & -1 & 41.0 & 43.9 & 36.3 & 39.9 & 161.1 \\
\hline \multicolumn{12}{|c|}{ summation } & 381.3 \\
\hline \multicolumn{13}{|c|}{ Effect of every variable on the target } \\
\hline \multicolumn{13}{|c|}{ Sum of square for every variable (SS) } \\
\hline \multicolumn{12}{|c|}{ Delivery time $=23.83+8.315 \mathrm{X}_{1}+3.77 \mathrm{X}_{2}-4.355 \mathrm{X}_{3}+4.355 \mathrm{X}_{1} \mathrm{X}_{2}-23.83 \mathrm{X}_{1} \mathrm{X}_{2} \mathrm{X}_{3}$} & 23.83 \\
\hline
\end{tabular}

Table 1. Continue.

\begin{tabular}{|c|c|c|c|c|c|}
\hline \multirow{2}{*}{ Total } & \multicolumn{5}{|l|}{ contract } \\
\hline & $\mathbf{A}$ & B & C & AB & $\mathbf{A B C}$ \\
\hline 64.4 & -64.4 & -64.4 & -64.4 & 64.4 & -64.4 \\
\hline 96.1 & 96.1 & -96.1 & 96.1 & -96.1 & -96.1 \\
\hline 59.7 & -59.7 & 59.7 & 59.7 & -59.7 & -59.7 \\
\hline 161.1 & 161.1 & 161.1 & -161.1 & 161.1 & -161.1 \\
\hline \multirow[t]{3}{*}{381.3} & 133.1 & 60.3 & -69.7 & 69.7 & -381.3 \\
\hline & 16.63 & 7.54 & -8.71 & 8.71 & -47.66 \\
\hline & 1107.22 & 227.25 & 303.6 & 303.6 & 9086.85 \\
\hline 23.83 & 8.315 & 3.77 & -4.355 & 4.355 & -23.83 \\
\hline
\end{tabular}

"Table1" illustrates the Effect of every variable is equal to $\frac{\text { contrast }}{2^{k-1} \times n}=\frac{\text { contrast }}{N \times n \div 2}$ where the $\mathrm{N}$ is the total number of runs. The main effect to $f \mathrm{~A}$ is $A=\overline{y_{A^{+}}}-y_{A_{-}}$which the average response is for $\mathrm{A}$ at high level minus the average of response for $A$ at low level. Therefore, the $A=\frac{133.1}{2^{2-1} \times 4}=16.63$, Sum of squares (SS) is the basis for the analysis of variance computation; the formula for the sum of squares is $S S_{A}=\frac{\text { contrast }^{2}}{2^{k} \times n}=\frac{(133.1)^{2}}{2^{2} \times 4}=1107.22$ To complete heijunka a matrix, we also need $\mathrm{SS}_{\mathrm{T}}$ and $\mathrm{SS}_{\mathrm{E}}$. In two-level factorial design. $S S_{T}=\sum_{i=1}^{2} \sum_{j=1}^{k} \sum_{k=1}^{n} y_{i j k}^{2}-\frac{y^{2}}{N \times n} \quad, \quad$ therefore the
$S S_{T}=(18.2)^{2}+(18.9)^{2}+\ldots .+(39.9)^{2}-\frac{(18.2+18.9+\ldots .+39.9)^{2}}{16}=1709.83$

and the sum of square error is $\mathrm{SS}_{\mathrm{E}}=\mathrm{SS}_{\mathrm{T}}-\mathrm{SS}_{\mathrm{A}}-\mathrm{SS}_{\mathrm{B}}-\mathrm{SS}_{\mathrm{C}^{-}}-\mathrm{SS}_{\mathrm{AB}^{-}}$ $\mathrm{SS}_{\mathrm{ABC}}, \mathrm{SS}_{\mathrm{E}}=1709.83-1107.22-227.25-303.6-303.6-9086.85=-$ 9318.69

Then the KPI of the heijunka a matrix will be adjusted according to this equation to calculate the KPI from node(i) to node $(\mathrm{j})$, Delivery time itoj $=23.83+8.315 \mathrm{X}_{1}+3.77 \mathrm{X}_{2}$ $4.355 \mathrm{X}_{3}+4.355 \mathrm{X}_{1} \mathrm{X}_{2}-23.83 \mathrm{X}_{1} \mathrm{X}_{2} \mathrm{X}_{3}$. "Fig.5" illustrates the ideal time for preparing orders is $1.6464 \mathrm{hrs}$, if the labors work 5 hrs after finishing their loading tasks, this means they can prepare between 39:54 orders/day. The best utilization for the drivers comes from working $8.0182 \mathrm{hrs} /$ trip plus unloading time to become $9.5182 \mathrm{hrs}$. 


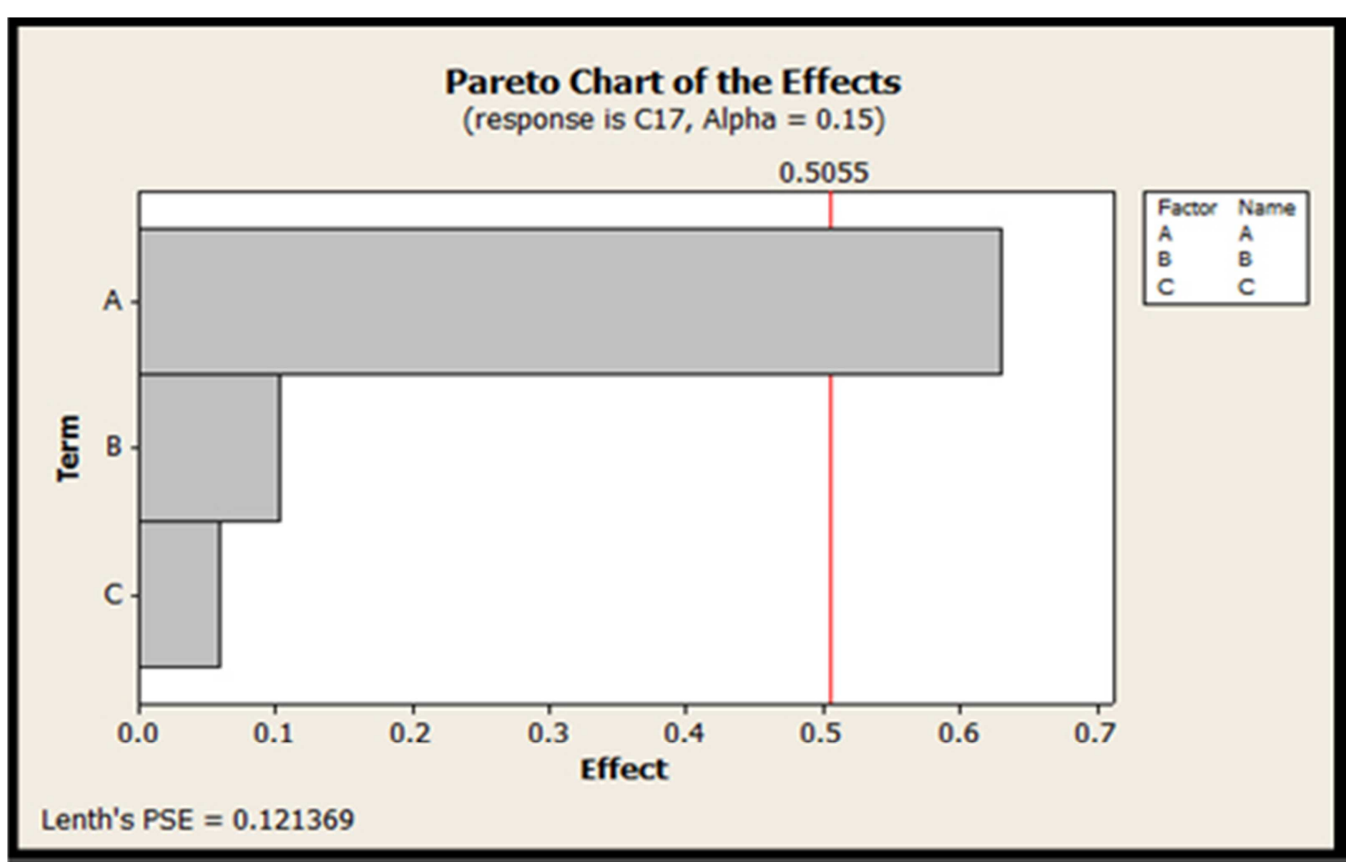

Fig. 4. The significant factor of KPI.

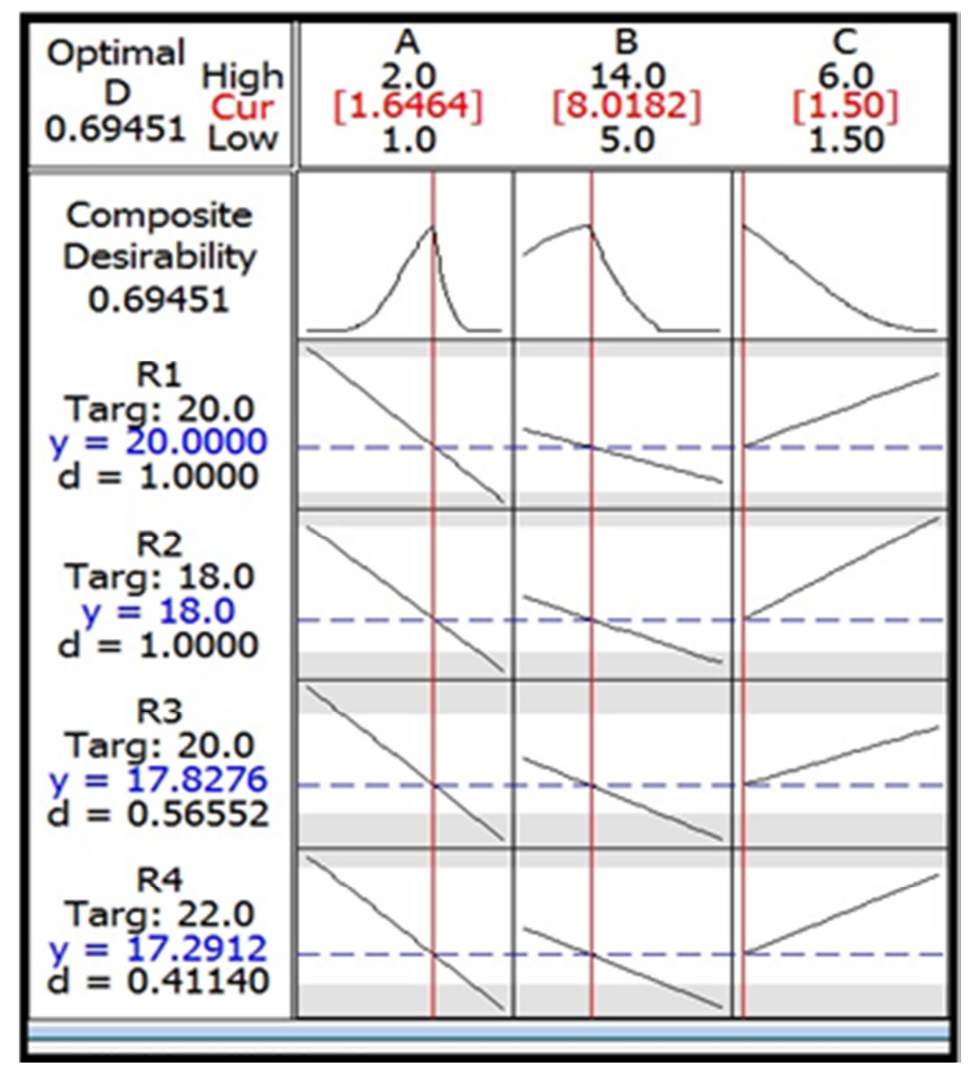

Fig. 5. The optimum values of KPI factors.

\section{Applying the Proposed Algorithm}

"Table2" states the logistics frequency between different stations. Where $X_{i j}$ is number of trips moved from station(i) to station(j), symbol $A$ is preserved to pure source node. The numbers appeared in "Table2" illustrate the KPI (delivery time $)=f($ preparing order time, travelling time, unloading time)* $\mathrm{f}^{*}$ handling factor. The frequency is considers, how many time will stay in this node. Any negative value is refused. The maximum values indicate the preferred place to start distribution from it. While the minimum values indicate the cells of cities (stations) that increase the efficiency of the delivery action. 


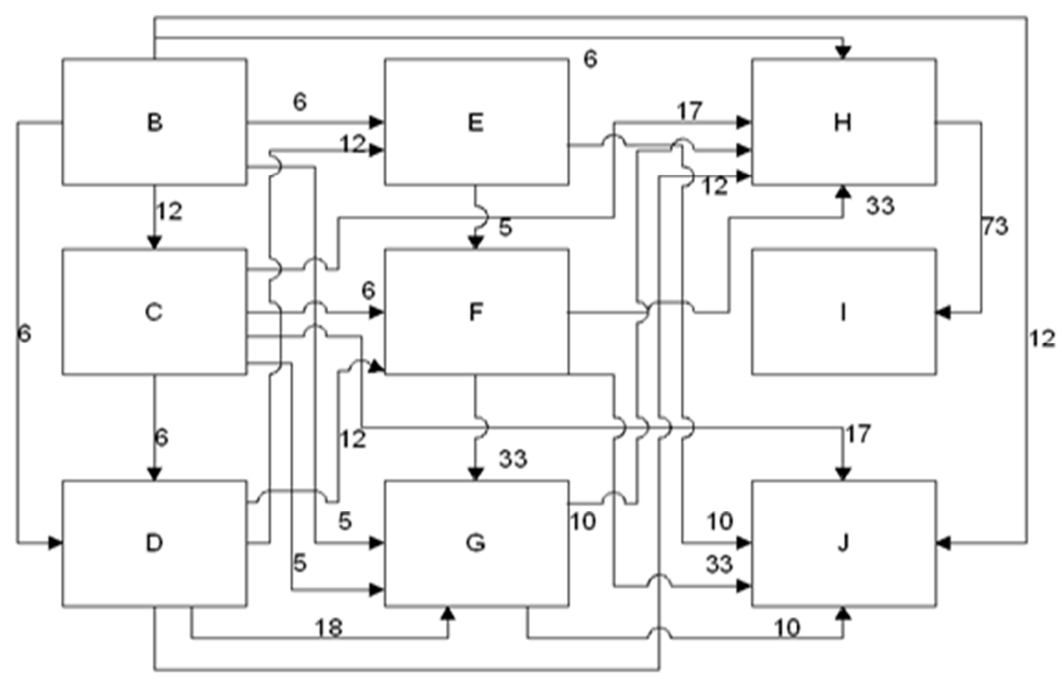

Fig. 6. The spaghetti diagram of "as-is".

Table 2. Heijunka tracking matrix: The delivery time among stations $\|$ nodes $\|$ cities.

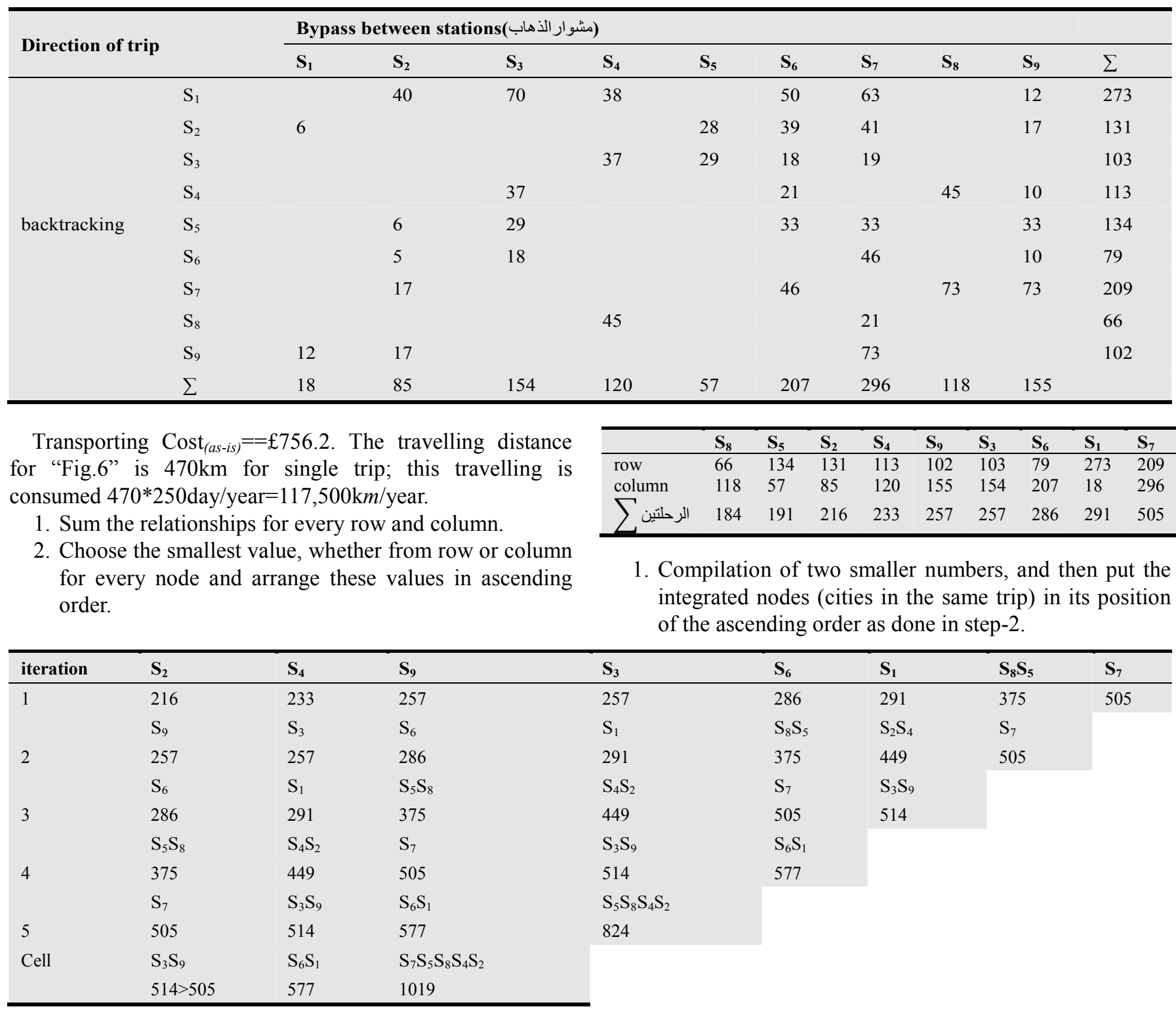


2. Continue until there remains not one single node, or the first cell for the collected values become greater than the larger summation of the end value for the delivery time for this city, whether for row or column. This number in this case is 505 .

3. Determine the cells as appeared in step-4.

\begin{tabular}{llll}
\hline Cells & $\mathrm{S}_{3} \mathrm{~S}_{9}$ & $\mathrm{~S}_{6} \mathrm{~S}_{1}$ & $\mathrm{~S}_{7} \mathrm{~S}_{5} \mathrm{~S}_{8} \mathrm{~S}_{4} \mathrm{~S}_{2}$ \\
\hline
\end{tabular}

4. Construct the Cells' table and its related nodes.

\begin{tabular}{|c|c|c|c|c|c|}
\hline Cell_1 & \multicolumn{5}{|c|}{ Related nodes ||cities } \\
\hline $\mathrm{S}_{3}$ & $\mathrm{~S}_{4}$ & $\mathrm{~S}_{5}$ & $\mathrm{~S}_{7}$ & $\mathrm{~S}_{6}$ & \\
\hline $\mathrm{S}_{9}$ & $\mathrm{~S}_{7}$ & $\mathrm{~S}_{5}$ & $\mathrm{~S}_{2}$ & $\mathrm{~S}_{1}$ & \\
\hline Cell_2 & \multicolumn{5}{|c|}{ Related nodes||cities } \\
\hline $\mathrm{S}_{6}{ }^{-}$ & $\mathrm{S}_{1}$ & $\mathrm{~S}_{7}$ & $\mathrm{~S}_{2}$ & $\mathrm{~S}_{5}$ & $\mathrm{~S}_{4}$ \\
\hline $\mathrm{S}_{1}$ & $\mathrm{~S}_{3}$ & $\mathrm{~S}_{7}$ & $\mathrm{~S}_{6}$ & $\mathrm{~S}_{2}$ & $\mathrm{~S}_{4}$ \\
\hline Cell_3 & \multicolumn{5}{|c|}{ Related nodes||cities } \\
\hline $\mathrm{S}_{7}$ & $\mathrm{~S}_{9}$ & $\mathrm{~S}_{1}$ & $\mathrm{~S}_{6}$ & $\mathrm{~S}_{2}$ & $\mathrm{~S}_{8}$ \\
\hline $\mathrm{S}_{5}$ & $\mathrm{~S}_{7}$ & $\mathrm{~S}_{6}$ & $\mathrm{~S}_{3}$ & $\mathrm{~S}_{2}$ & \\
\hline $\mathrm{S}_{8}$ & $\mathrm{~S}_{7}$ & $\mathrm{~S}_{4}$ & & & \\
\hline $\mathrm{S}_{4}$ & $\mathrm{~S}_{8}$ & $\mathrm{~S}_{1}$ & $\mathrm{~S}_{3}$ & & \\
\hline $\mathrm{S}_{2}$ & $\mathrm{~S}_{7}$ & $\mathrm{~S}_{6}$ & & & \\
\hline
\end{tabular}

5. Arrange the related nodes with respect to its strong delivery relations, and construct the multi-floor trip, which depends on TPS. Which suggest to build the store in $\mathrm{S}_{7}$ position,

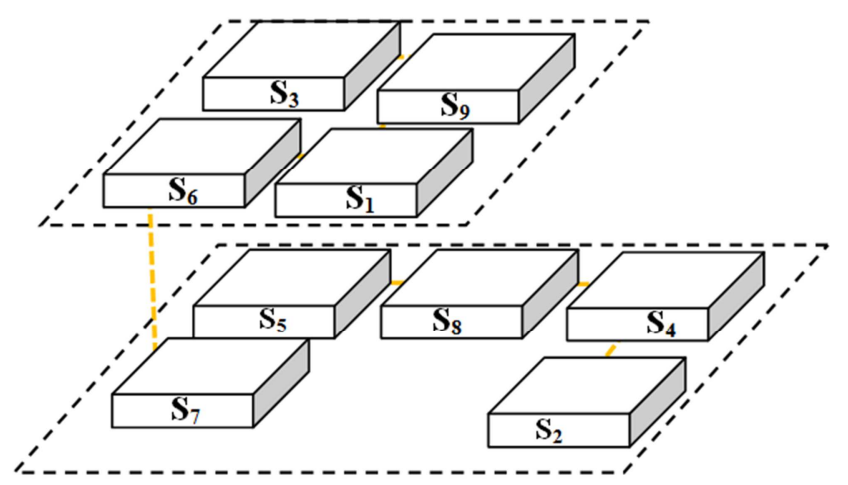

Fig. 7. New 3-D Gemba stations "Should-be".

Transporting Cost (heijunka) $=80,000 \mathrm{~km} /$ year, these procedures which present "Fig.7" were save $30 \%$ of costs. "Table3" illustrates the developing occurred by applying proposed procedures than current as-is situation.

Table 3. The Comparison between "proposed algorithm" and "as-is" state.

\begin{tabular}{llll}
\hline Attributes & As-is & To-be & Developing\% \\
\hline Delivery Lead Time "min" & 713 & 595 & $16.5 \%$ \\
Travelling distance for trip km/year & 117,500 & 80,000 & $32 \%$ \\
Travelling cost for complete trip£ & 645.6 & 482.6 & $30 \%$ \\
Fatigue and strength & High & Very Low & $28 \%$ \\
Utilization to meet target & X & Up & \\
Inter-cell material handling turns & Complex & good & \\
Trip utilization & Low & enhance & deterministic \\
Number of cells & None & Minutes & $63 \%$ \\
Quality feedback & Days & 2001983 & $53 \%$ \\
The Profits relate void cost & 1227123 & 147,235 & \\
The Delivery Costs & 315,234 & & \\
\hline
\end{tabular}

\section{The Conclusion}

The dynamic Gemba VSM procedures are affected by the delivery time and costs. The proposed procedures are compared with as-is situation and aid the TSP to enhance the solution. The Delivery lead time was developed by $16.5 \%$, the travelling time (NNVA) was developed by $32 \%$ and the travelling cost was reduced in average by $30 \%$. The proposed procedures present a cellular of items, which increase from the labor utilization and quality feedback. Also increase the profits by $63 \%$, all this information was illustrated in"Table3".

\section{References}

[1] Aiello G, Enea M, Galante G,. Multi-objective approach to facility layout problem by genetic search algorithm and Electre method. Robotics and Computer-Integrated Manufacturing, 22, 447-455.(2006)
[2] Aleisha EE, Lin L. For effectiveness facilities planning: Layout optimization then simulation, or vice versa? In Proceedings of the (2005).

[3] Asef-Vaziri A, Laporte G. Loop based facility planning and material handling. European Journal of Operational Research, 164 (1), 1-11, (2005).

[4] Bazargan-Lari M., Kaebernick H. Intra-cell and inter-cell layout designs for cellular manufacturing. International Journal of Industrial Engineering \pm Applications and Practice $3,139 \pm 150,(1996)$.

[5] Bazargan-Lari M., Kaebernick H. An approach to the machine layout problem in a cellular manufacturing environment. Production Planning and Control 8(1), 41 \pm 55 , (1997).

[6] Baykasoglu, A., Dereli, T., Sabuncu, I. An ant colony algorithm for solving budget constrained and unconstrained dynamic facility layout problems. Omega, 34(4), 385-396, (2006).

[7] VanCamp, D.J., Carter, M.W., and Vannelli, A. Anon-linear optimization approach for solving facility layout problems. European Journal of Operational Research57, 174 $\pm 189,(1992)$. 
[8] Heragu, S. S. Group technology and cellular manufacturing. IEEE Transactions on Systems, Man, and Cybernetics 24(2), (1994).

[9] Heragu, S.S. and Kusiak, A. Efficient models for the facility layout problem. European Journal of Operational Research $53,1 \pm 13,1991$.

[10] Jumpup $\wedge$ Womack, Jim. Gemba Walks. Lean Enterprise Institute, Inc.p.348.ISBN978-1-934109-15-1,(2011).

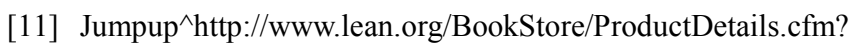
SelectedProductId $=320$

[12] Jumpup ^ ${ }^{\wedge}$ http://ajm.sagepub.com/content/27/4/352.extract
[13] Jumpup ^ Andrew Castle, Rachel Harvey. "Lean information management: the use of observational data in healthcare".InternationalJournalofProductivityandPerformanc eManagement, Vol. 58 Iss: 3, pp. 280-299. ISSN 1741-0401., (2009)

[14] Jumpup ${ }^{\wedge}$ Mann, David W. (2005). Creating a lean culture; tools to sustain lean conversions. Productivity Press. p. 211. ISBN1563273225.

[15] H. Ku, H. Wang, N. A solution to the unequal is a facilities layout problem by genetic algorithm. Computers in Industry, 56(2), 207-220, (2005). 